\title{
Graphitic Carbon Nitride Co-doped with Sulfur and Yttrium for Efficient Visible-Light Photocatalytic Performance
}

Xin Baił, Man Lił, Jinlun Li, Xi Rao, Shaohui Zheng*, and Yongping Zhang*

School of Materials and Energy, Southwest University, Chongqing 400715, China

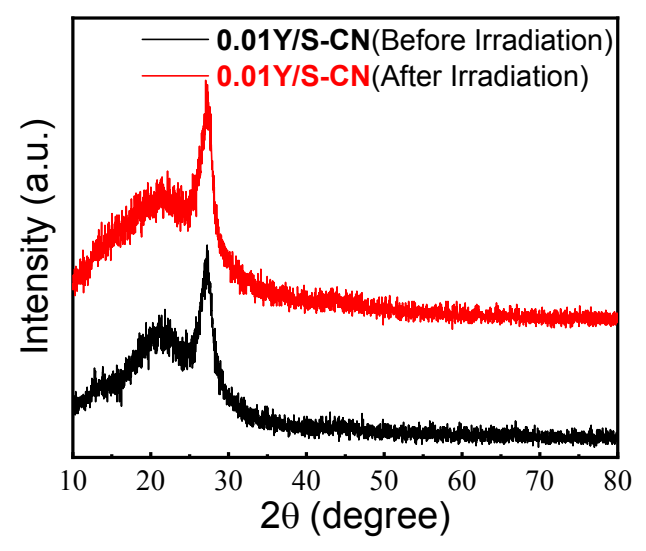

Figure S1. XRD patterns of $0.01 \mathrm{Y} / \mathrm{S}-\mathrm{CN}$ before and after photocatalytic reaction.

XRD patterns of $0.01 \mathrm{Y} / \mathrm{S}-\mathrm{CN}$ did not show any obvious change, verified the photocatalyst was stable under visible light irradiation. 


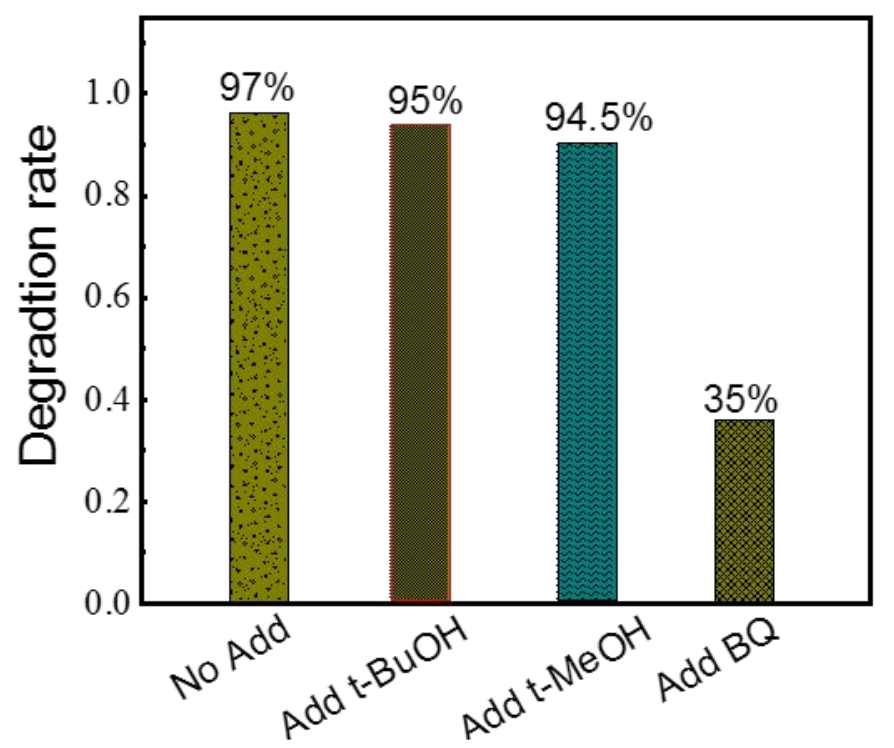

Figure S2. Degradation rate of $\mathrm{Y} / \mathrm{S}-\mathrm{CN}$ in the presence of various scavengers.

The degradation rate did not change obviously upon adding t-MeOH and t-BuOH in the photocatalytic process, as shown in Fig. S2, implying that hydroxyl radicals and holes have a minor effect on the RhB degradation. The dramatic drop in the degradation rate of $\mathrm{RhB}$ upon adding $\mathrm{BQ}$ solution indicates that the main active superoxide radicals play a vital role during the $\mathrm{RhB}$ degradation process, consistent with the EPR results.

According to the calculated DOS in Fig. 10, the valence bands of the three compounds are mainly composed of carbon + nitrogen atomic orbitals, while the conduction bands of pure $\mathrm{g}_{-} \mathrm{C}_{3} \mathrm{~N}_{4}, \mathrm{~S}$-doped, and Y-doped g- $\mathrm{C}_{3} \mathrm{~N}_{4}$ are also mainly contributed by carbon + nitrogen atomic orbitals. 


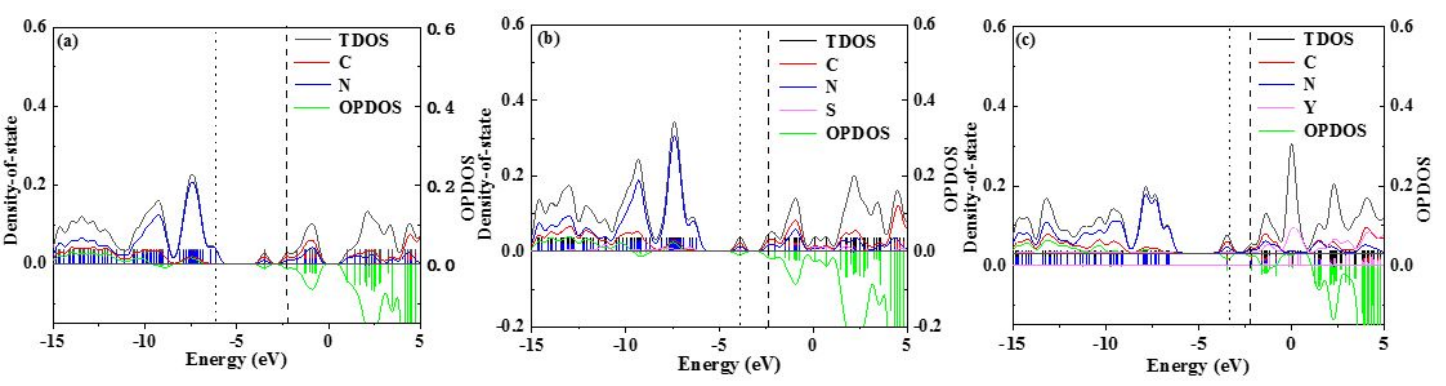

Figure S3. Calculated total, partial, and overlapped population density of states of pure (a), S- doped (b), and Y-doped g- $\mathrm{C}_{3} \mathrm{~N}_{4}$ (c). 